\title{
تحليل محتوى كتاب دروس اللغة العربية الجزء الأول للإمام الزركثى والإمام الشبانى من حيث التراكيب وأثرها في فهم النصوص الإسلامية
}

\author{
Hurriyatus Sa'adiyah \\ LAIN Bukittinggi,ham909398@gmail.com
}

Indra Saputra

Pesantren Thawalib Gunung Padang Panjang, abakfathun@gmail.com

\begin{tabular}{|l|l|l|}
\hline Diterima: 12 Januari 2018 & Direvisi $: 23$ Maret 2018 & Diterbitkan:30Juni 2018 \\
\hline
\end{tabular}

\begin{abstract}
Textbooks are one of the most important things in the learning process. Therefore, teachers and educators must prepare it very well so that the desired learning objectives can be achieved. The use of textbooks must adjust to the methods, objectives, and learning media. The purpose of this study is to analyze the contents of the book Durus al Lughah al Arabiyah Juz I by Imam Zarkasyi and Imam Syubani from one aspect of the language, namely tarkib (sentence structure). As is known, mastery of tarkib is very important in understanding Islamic teachings, because the source, the Quran, Hadith, and the books of Islamic scholars, use Arabic. Without good mastery, texts that speak. Arabic can be wrong and difficult to understand. The method used in this study is the method of content analysis by analyzing this book Durus al Lughah al Arabiyah Juz. I. The results of the research are that the author did not find special material on tarkib learning in this book. In accordance with the purpose of writing, namely the application of speech, the tarkib is directly learned in a sentence. This sentence is given from a simple form and gradually changes to a more complex sentence accompanied by exercises on each material. Among the forms of tarkib training are question and answer, word changes, sentence enhancements, etc.
\end{abstract}

Keywords: Textbook, Element of Language, Tarkib.

\begin{abstract}
Abstrak
Buku ajar adalah salah satu hal yang sangat penting dalam proses pembelajaran. Oleh karena itu, para pengajar dan pendidik harus mempersiapkannya dengan sangat baik sehingga tujuan pembelajaran yang diinginkan dapat tercapai. Penggunaan buku ajar harus menyesuaikan dengan metode, tujuan, dan media pembelajaran. Tujuan penelitian ini adalab untuk menganalisis isi buku Durus al Lughah al Arabiyah Juz I karangan Imam Zarkasyi dan Imam Syubani dari salab satu segi unsur bahasanya, yaitu tarkib (struktur kalimat). Sebagaimana yang diketabui, penguasaan tentang tarkib sangat penting dalam memahami ajaran Islam, karena sumbernya, al Quran, Hadis, dan kitab-kitab ulama Islam, memakai bahasa Arab. Tanpa penguasaan yang baik, teks-teks yang berbahasa Arab bisa salah dan sulit dipahami. Metode yang digunakan dalam penelitian ini adalab metode analisis konten dengan menganalisis ini buku Durus al Lughah al Arabiyah Juz. I. Adapun hasil penelitiannya adalah bahwa penulis tidak menemukan materi khusus pembelajaran tarkib dalam buku ini. Sesuai dengan tujuan penulisannya yaitu penerapan berbicara, maka tarkib langsung dipelajari dalam sebuah kalimat. Kalimat ini diberikan dari yang bentuknya sederhana dan secara bertahap berubah ke kalimat yang lebih komplek disertai dengan latihanlatihan pada setiap materi. Di antara bentuk latihan tarkibnya adalah tanya jawab, perubahan kata, penyempurnaan kalimat, dan lain-lain.
\end{abstract}

Kata Kunci: Buku Ajar, Unsur Bahasa, Tarkib. 
ثالثاً: الكفاية الثقافية، ويقصد بها فهم ما تحمله اللغة

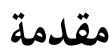

العربيـة مـن ثقافـة، تعـبّر عـن أفكـار أصسحابها

وبتحاربهم وقيمهم وعاداتم وآدابهم وفنوهم. وعلى

مــرس اللغـة العربيـة تنميـة هـذه الكفـايات

الثلاث، لـدى طلابـه مسن بدايـة بـرنامج تعليم

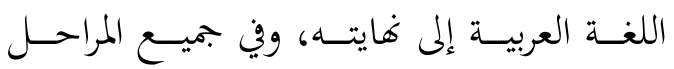

$$
\text { والمستويات. }
$$

أن تعليم اللغة العربية يتكون من أربع مهارات

وهي مهارة الاستماع ومهارة الكلام ومهارة القراءة

ومهارة الكتابة.تعد مهارة الكلام إحدى المهارات اللغوية الأساسية، لأن اللغة في الأصل كلام.تْوالكلام في اللغة الثانية من المهارات الأساسية التي تمثل غاية من غايات الدراسة اللغوية. وإن كان هو نفسه وصيلة

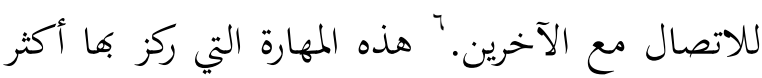
المعاهد الاسلامية بالخصوص المعاهد الاسلامية

وفيما يلي بجموعة من التوجيهات العامة التى

قد تسهم في تطوير تدريس مهارة الكالام في العربية

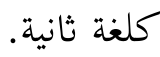

1. تدريس الكلام يعني ممارسة الكلام: يقصد بذلك

أن يتعرض الطالب بالفعل إلى مواقف يتكلم فيها

$$
\text { بنفسه لا أن يتكلم غيره عنه. }
$$

r. أن يعبر الطلاب عن خبرة: يقصد بذلك ألا يكلف الطلاب بالكالام عن شيء ليس لديهم

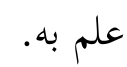

4 Zainul Arifin, Mawad Dirasah fi Thuruq Ta'lim al Lughah al 'Arabiyyah, (Padang: t.p., t.th), h.2-3.

${ }^{5}$ Umar al Shadiq Abdullah, Ta'lim al Lughah al 'Arabiyyah li al Nathiqin bi Gairiha, (Khurtum: al Dar al Alamiyyah, 2008), h.75.

${ }^{6}$ Rusydi Ahmad Thu'aimah, op.cit., h.160.

${ }^{1}$ Muhammad Ali al Siman, al Taujih fi Tadris al Lughah al 'Arabiyyah, (Kairo: Dar al Ma'arif, 1982), h.1.

2 Rusydi Ahmad Thua'imah, Ta'allum al 'Arabiyyah li Ghairi al Nathiqin biha wa Asalibuha wa Manabijuha, (Rabat: Isesco, 1989), h. 11.

3 Muhammad Ali al Khauli, Asalib Tadris al Lughah al 'Arabiyyah, (Riyad: t.p, 1989), h.32. 
يحسن المعلم اختيار الموضوعات التى يتحدث

$$
\text { الطلاب فيها. }
$$

تعليم مهارة الكلام له أهداف، وهي:

1. أن ينطق المتعلم أصوات اللغة العربية، وأن يؤدي

أنواع النبر والتنغيم المختلفة بطريقة مقبولة من أبناء

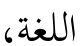

r. أن ينطق الأصوات المتجاورة والمتشابهة، r. أن يستخدم الحركات الطويلة والحركات القصيرة، ء. أن يعبر عن أفكاره مستخدما النظام الصحيح لتركيب الكلمة في العربية خاصة في لغة الكلام

الفصحى6

○. أن يكتسب ثروة لفظية كامية مناسبة لعمره وحاجته وأدواره وخبراته وأن يستخدم هذه الثروة في إتمام عمليات اتصال عصرية، T. أن يستخدم بعض أشكال الثقافة العبية الإسلامية المناسبة لعمرة ومستواه الثقافي وطبيعة عمله، وأن يكتسب بعض المعلومات الأساسية

$$
\text { عن التراث العربي الإسلامي، }
$$

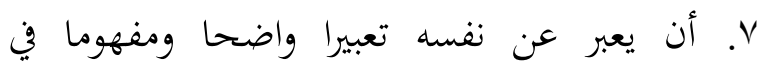

$$
\text { مواقف الحديث البسيطة، }
$$

^. أن يفكر باللغة العربية ويتحدث بها بشكل متصل

$$
\text { ومترابط لفترات زمنية مقبولة. ^ }
$$

وفي استعداد تعليم اللغة العربية، لمهارة الكلام

أو المهارات الأخرى،هناك الأشياء الكثيرة التى لزم للمعلم اهتمامها في استعداد تعليم اللغة العربية، كمنهج التعليم أو الأهداف المرجوة أو طروق التعليم

${ }^{7}$ Ibid., h.162-160.

8 Abdurrahman bin Ibrahim Fauzan, I'dad Mawad Ta'lim al Lughah al 'Arabiyah li Ghairi al Nathiqin biha, (t.t: t.p, 1428 H), h.42. r. التدريب على توجيه الإنتباه: ليس الكلام نشاطا آليا يردد فيه الطالب عبارات معينة وقتما يراد منه تهئ الكام. إن الكلام نشاط عقلي مركب أنه يستلزم القدرة على تمييز الأصوات عند سماعها و نطقها. والقدرة على تعرف التراكب وأن اختلافها يؤدي إلى اختلاف المعنى. ع. عدم المقاطعة وكثرة التصحيح: من أكثر الأشياء حرجا للمتحدث و و إحباطا له أن يقاطعه الآخرون. وإذا كان هذا يصدق على المتحدثين في لغتهم الأولى فهو أكثر صدقا بالنسبة للمتحدثين في لغات ثانية. إن لديهم من العجز

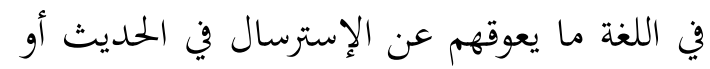

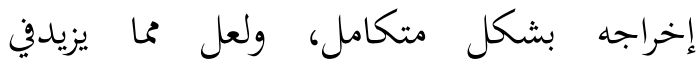
إحساسه بهذا العجز أن يقاطعه المعلم. ويرتبط هذا أيضا ألا يلح المعلم في تصحيح أخطاء

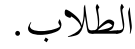
๑. مستوى التوقيعات: من المعلمين من تزيد توقعاهما كما سبق القول عن الإمكانات الحقيقية للطالب، فيظل يراجع الطالب، ويستحثه على استيفاء القول ثم يلومه إن لم يكن عند مستوى

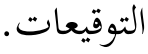
T. التدرج: تعلم هذه المهارة لا يحدث بين يوم وليلة، ولا بين عشية وضحاها. إها عملية تستغرق وقتا وتطلب من الصبر والجها والحكمة ما ينبغي أن يملكه المعلم. وعليه أن يهيء من مواقف الكلام ما يتناسب مع كل مستوى من مستويات

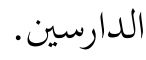
V. قيمة الموضوع: تزداد دافعية الطلاب للتعلم كلما كان ما يتعلمونه ذا معنى عندهم. وينبغي أن 
التعلم، ومصدر تعليمي يلتقي عنده المعلّم والمتعلّم، حمة

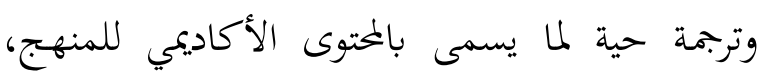
ولذلك تعتبر نوعية وجودة الكتاب المدرسيّ من أهم الأمور التي تشغل المهتمين بالمتوى والمادة التعليمية

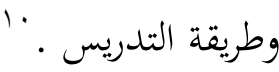

إعداد مواد لتعليم اللغة العربية لغير الناطقين

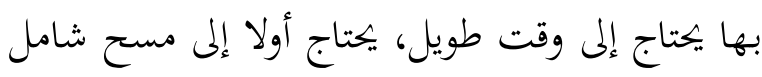

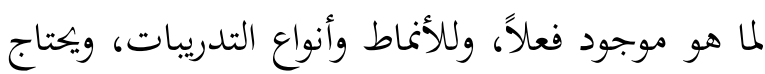
إلى ضبط تام للمفردات وللتراكيب، ولدرجة من فران

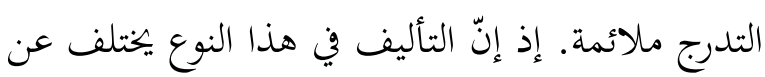
غيره. وإعداد مواد اللغة لغير الناطقين بها صعب، لأنه يجتاج إلى ضبط كل شيء، فضبط المفردات والتراكيب يجعل من الاعتماد على النصوص الأصلية أمراً صعباً،

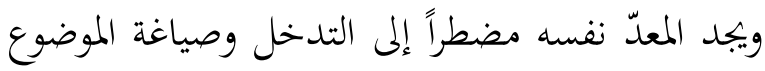
أو جزء منه بنفسه.

استخدام كتاب التعليم واحد من الطرق

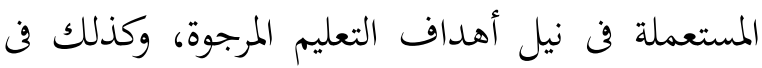
تعليم المهارة اللغوية، ليصل إلى أهداف تعليم المهارة

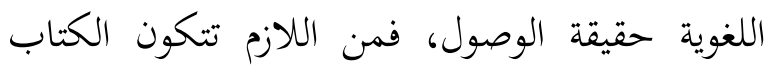

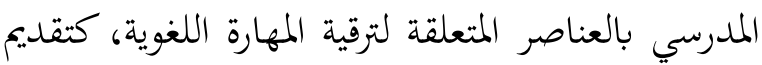
الأصوات والمفردات والتراكيب وأشكال التدريبات

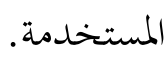

التراكيب هي عنصر من العتاصر اللغوية ولذلك كالعتصر اللغوية هي متصلة في تعليم مهارة

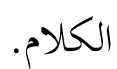

إن أوجه الاختلاف بين اكتساب العربية بوصفها لغة أولى، وتعلمها بوصفها لغة ثانية، يُعزَز الئز Mawad...., h.2.
أو المواد التعليمية أو الخلفية المتفرقة بين التلاميذ وما

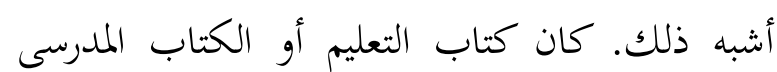

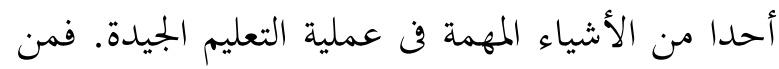

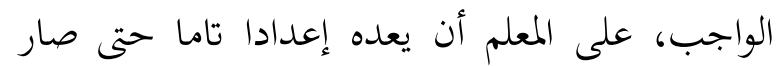
هذا الكتاب دليلا له للوصول إلى الأهداف التعليمية

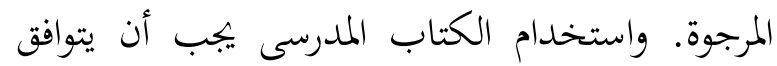
بمنهج التعليم والأهداف المرجوة ووسائل التعليم وخصائص التلاميذ وغيرها.

والكتاب المدرسي، من بين أنواع الكتب وعين الأخرى، ذو مكانة خاصة في التنمية الثقافية لهذا الشعوب. إنه وعاء المعرفة، وناقل الثقافة ومحور العملية التربوية وأداة التواصل بين الأجيال، ومصدر المعلومات التهات المعات التهات الأساسي عند كثير من المعلمين. والدعوة إلى الثناهم الدولي وبناء المواطن العالي تأخذ طريقها في العملية التربوية عن طريقة الكتاب المدرسي.

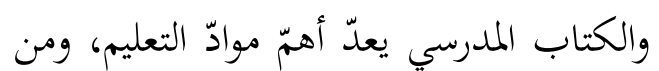

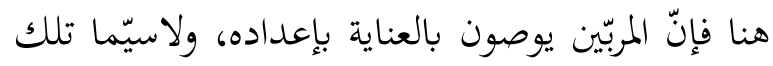
الموادّ التي تعنى بتعليم اللغة العربية لغير الناطقين بها،

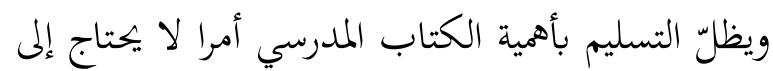
تقرير، فبالرغم مما قيل ويقال عن تكنولوجيا التعليم

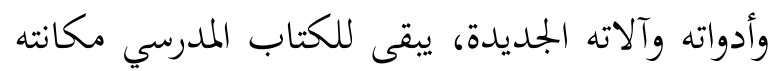
المتفردة في العملية التعليمية. فعملية التدريس أياً كان نوعها أو نمطها أو مادتها ومحتواها تعتمد اعتماداً كبيراً على الكتاب المدرسي، فهو يمثل بالنسبة للمتعلّم أساساً باقياً لعملية تعلّم منظمة، وأساساً دائماً لتعزيز

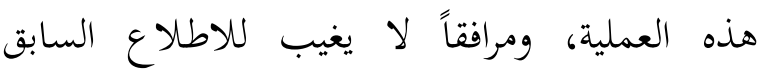

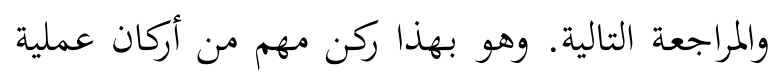

${ }^{9}$ Rusydi Ahmad Thu'aimah, Dalil 'Amal fi I'dad al Mawad al Ta'limiyah li Baramij Ta'lim al 'Arabiyah, (Makkah: Ummul Qura. 1985), h.27-28. 
دعوى ضرورة إيجاد كتب لتعليم العربية للناطقين بها، ومن التدريبات التي يمكن أن تستخدم في الكتاب مختلفة عن كتب تعليمها للناطقين بغيرها. وقد يكون تدريبات: التكرار، والاستبدال، والتحويل، والسؤال النحو المدرس لكل منهما، أهم اختلاف ينبغي أن والجواب، والتوسعة والاختصار. وينبغي المدرس إجراء تنطوي عليه تلك الكتب. فثمة أمور من النحو التدريبات النحوية شفهياً أولاً، ثم قراءة، ثم كتابة. كما اكتسبها الناطقون بالعبية قبل دخولمم المدرسة، ولن يجب أن يؤديها الطلاب جماعياً وثنائياً وفردياً. I يكونوا في حاجة إلى تعلمها، لأها باتت جزءاً من وهذه أنواع تدريب على بناء التراكيب اللغوية:

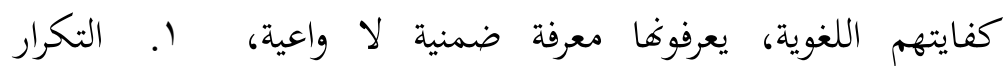

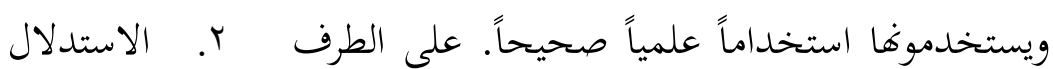
الآخر نجد الطلاب الآخرين يحتاجون من النحو إلى ب. النموذج: أنا طالب من مصر

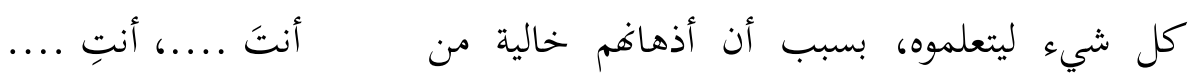

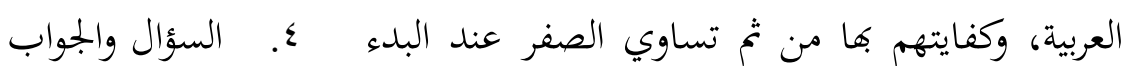

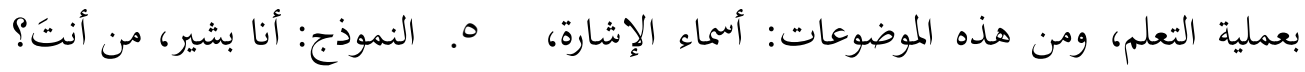

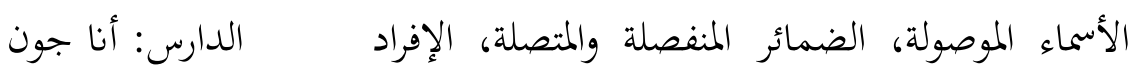

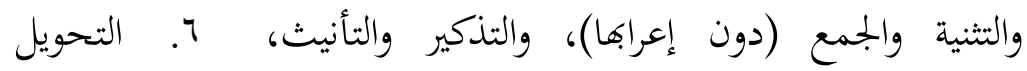
التعريف والتنكير، المطابقة بين الصفة والموصوف، النموذج: أنا من مصر / أنا مصري

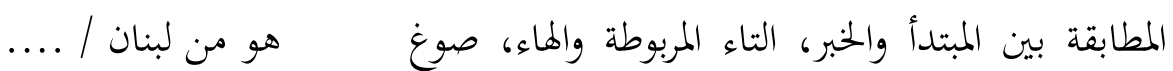

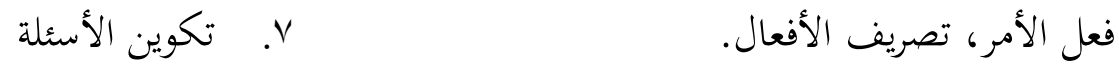
وهنـاك بعض الموضسوعات الصوتية، مثل: ال النموذج: هذا مكتب / هل هذا مكتب؟

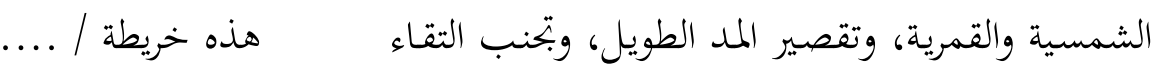

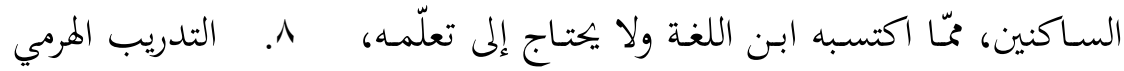

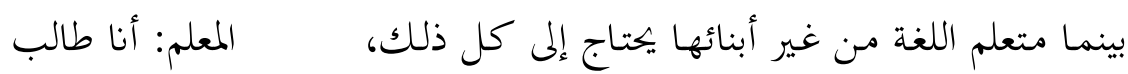
سواء من أبواب القواعد أو من المسائل الصوتية. ' ل وقد يجسن في أوّل الكتاب-إلى حد كبير- - المعلم: سوداني الاعتماد على تدريبات الأنماط (القوالب)، وهي الدارس ب: أنا طالب سوداني التدريبات التي يسيطر المدرس فيها سيطرة تامة على 9. التدريب التسلسلي استجابة الطالب، حيث إنّ هناك طريقة واحدة الدارس ا: (موجها حديثه إلى الدارس r): أنا

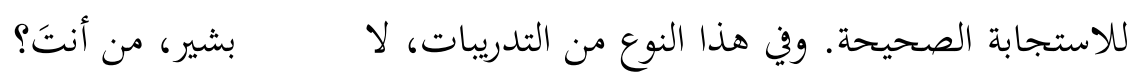
يجتاج الطلاب إلى فهم ما يقولونه، لأداء التدريب. 
بناء على ما كتب في السابق، رغبت الكاتبة تحليل مضمون كتاب دروس اللغة العربية الجزء الأول للإمام الزركشى والإمام الشبانى من حيث العناصر اللغوية

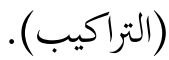
كتاب دروس اللغة العربية الجزء الأول للإمام الزركشى هلي ليحيل

والإمام الشبانمن حيث العناصر اللغوية (التراكيب).

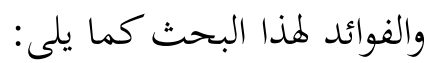

1. يرجى هذا البحث أن يكون مفيدا لتطور العلوم في في لفئ

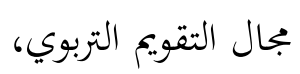

r. أن تكون نتيجة هذا البحث مرجعا لمعلم اللغة العربية بالمعاهد أو المدارس في اكتساب المهارات
أما غرض هذا البحث هو لتحليل محتوى

الدارس r: (موجها حديثه إلى الدارس (): أنا

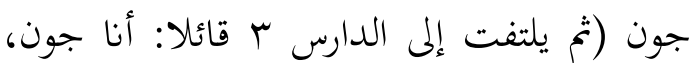

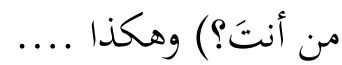

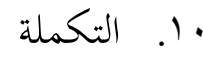
النموذج: يكتب الطالب .... (الدرس).

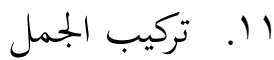
النموذج: عربي - سامي - طالب / مابمي

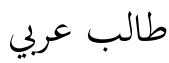

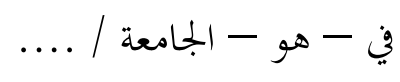

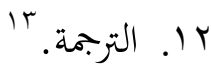

الاستيلاء عن التراكيب مهمة في فهم الدين الإسلام، لأن مراجعه القرأن و الحديث وكتب العلماء القديية وكلها باللغة العربية. كما قال الله تعالى في

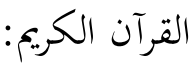

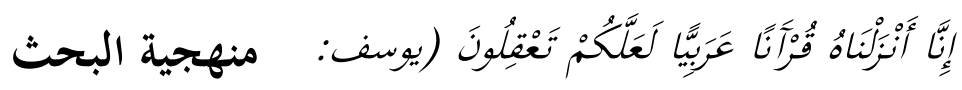

تستخدم الكاتبة طريقة تحليل المتوى.

وطريقةتحليل المتوى هي طريقة البحث المنظمة

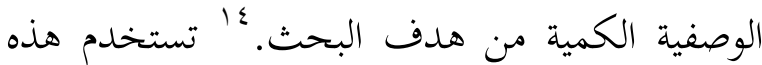
الطريقة في تحليل مضمون ومتوى كتاب دروس اللغة العربية الجزء الأوللإمام الزركشى والإمام الشبانمن

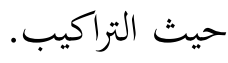

$$
\text { طريقة تحليل المعلومات: }
$$

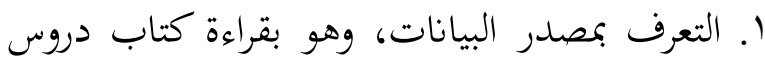
اللغة العربية الجزء الأول لتحليل هذا الكتاب، r. الوصف، والمراد به وصف كتاب دروس اللغة العربية

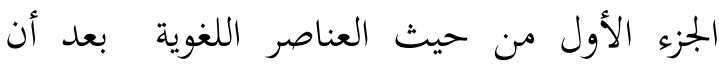

$$
\text { نالت الكاتبة البيانات من مصدرها، }
$$

14 Lufri, Metodologi Penelitian, (Padang: Universitas Negeri Padang, 2005), h. 57.
13 Rusydi Ahmad Thu'aimah, Dalil 'Amal..., h.240-243. تحليل محتوى كتاب ...
كان الكتاب المدرسي من العوامل المهمة في الوصول إلى أهداف التعليم. ومنه كتاب دروس اللغة العربية، ألفه إمام زركشى وإمام شبانى. وكانا معلمان فن معهد دار السلام كنوتور. وقد استخدم معهد دار السلام كونتور بجميع معاهد فروعه هذا الكتاب منذ الزمان. تتعلق هذا الكتاب من جزئين، للجزء الأول 179 صفحة، استخدم هذا الكتاب طريقة المباشرة في أول الدرس واستمرت بطرق أخرى في وسطه إلى

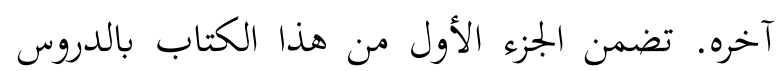
الأساسية الملائمة بالمحادثة اليومية في أول بابه. 


\begin{tabular}{|c|c|c|c|}
\hline مواد التراكيب & التراكيب & رقم الدرس & الرقم \\
\hline ذأهذ مقعد؟ لا، & & & \\
\hline همل مسل، مدرسة، هنا & هنا وهناك & $\varepsilon$ & $\varepsilon$ \\
\hline 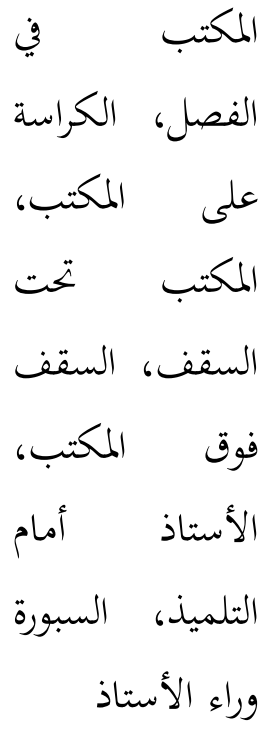 & 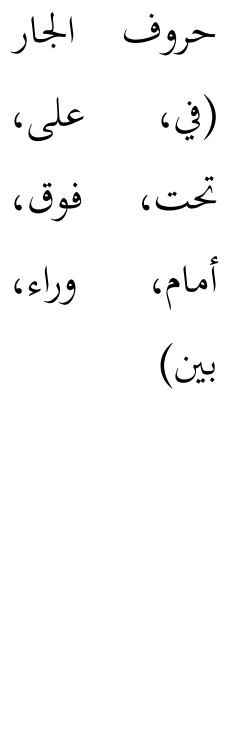 & 0 & 0 \\
\hline 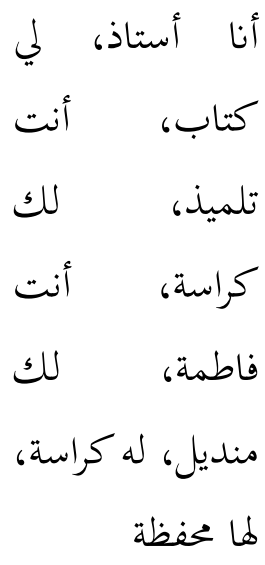 & 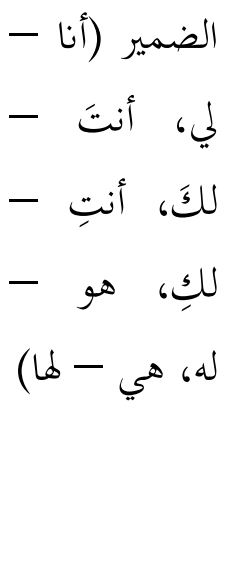 & 7 & 7 \\
\hline منزلي، & (أنا_....ي، & V & V \\
\hline
\end{tabular}

r. التفسير والتحليل، والمراد هنا بعد أن وصّفت النقات الكاتبة الظواهر الموجودة المتعلقة بالموضوع، تفستر

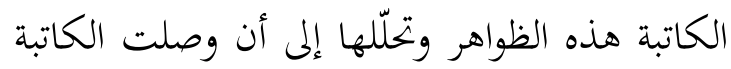

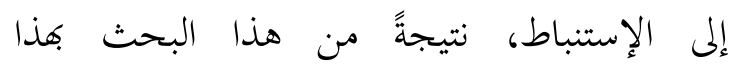
الموضوع. (الإن.

محتوى كتاب دروس اللغة العربية الجزء الأول للإمام الزركشى والإمام الثبانى من حيث التراكيب

هذا الفهرس التفصيلي للتراكيب في كتاب دروس اللغة العربية الجزء الأول للإمام الزركشى والإمام

\begin{tabular}{|c|c|c|c|}
\hline مواد التراكيب & التراكيب & الدرس & الرقم \\
\hline ذأهذا هذب، ما هذاب، ذلك & ذلككر) الإسذا، & 1 & 1 \\
\hline 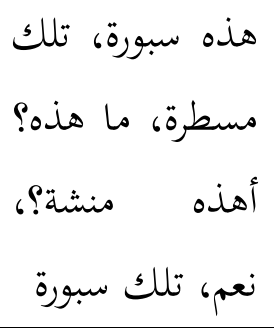 & تلكؤنث (هذه، : الإشارة & r & r \\
\hline 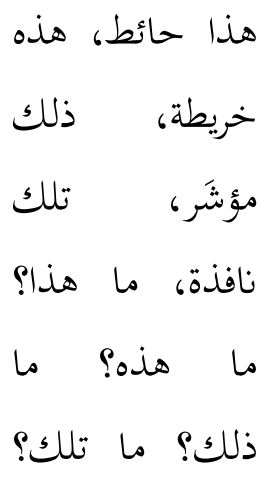 & 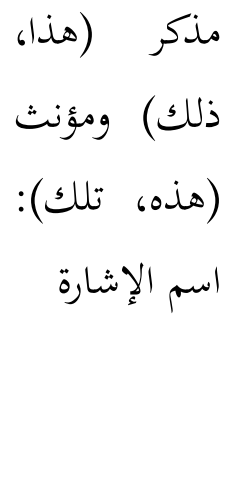 & $r$ & $r$ \\
\hline
\end{tabular}




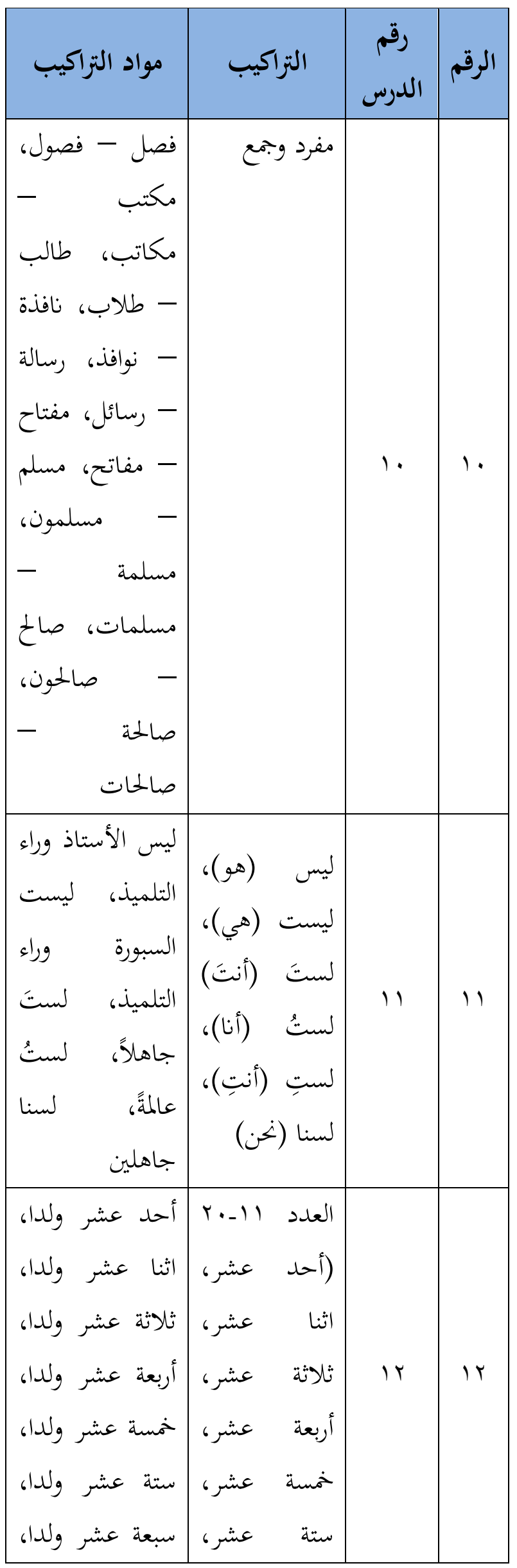

\begin{tabular}{|c|c|c|c|}
\hline مواد التراكيب & التراكيب & رقم & الرقم \\
\hline 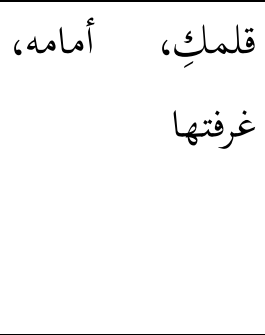 & 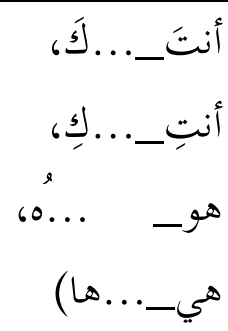 & & \\
\hline 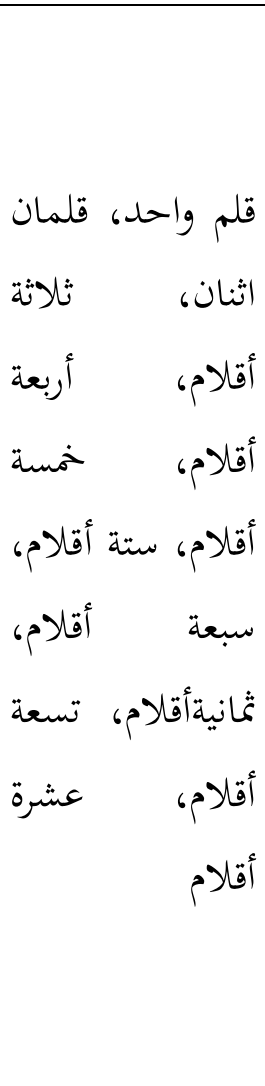 & 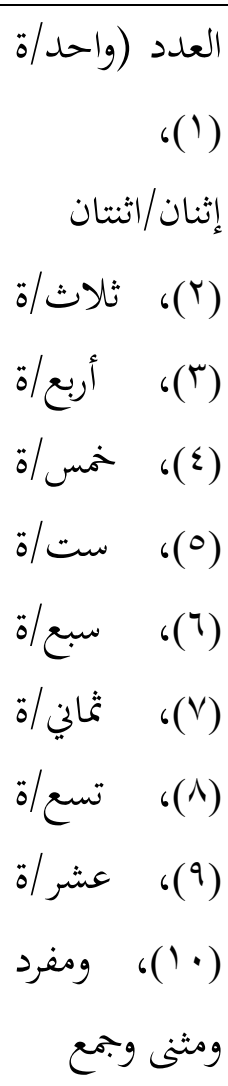 & $\wedge$ & $\wedge$ \\
\hline تمجلة & ومثنى و.مع العدد، ومفرد & 9 & 9 \\
\hline
\end{tabular}




\begin{tabular}{|c|c|c|c|}
\hline مواد التراكيب & التراكيب & رقم الدرس & الرقم \\
\hline سريعة & & & \\
\hline 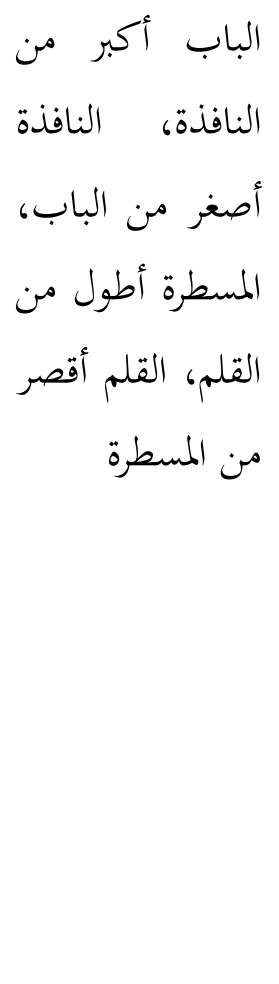 & 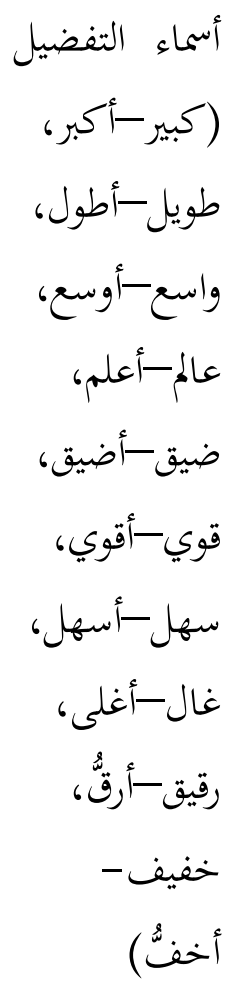 & 10 & 10 \\
\hline 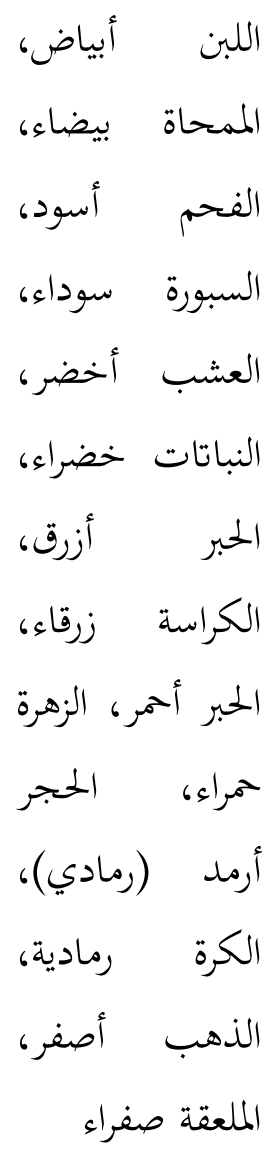 & الألوان (مذكر & 17 & 17 \\
\hline
\end{tabular}

\begin{tabular}{|c|c|c|c|}
\hline مواد التراكيب & التراكيب & رقم الدرس & الرقم \\
\hline تمانية عشر ولدا، & 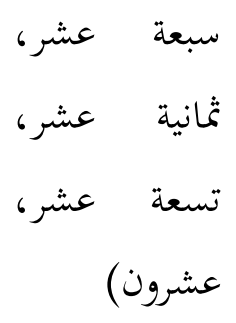 & & \\
\hline رسمال رسالةً & عشرة، عشرة ع عشرة ع عشرة & $1 \pi$ & IT \\
\hline 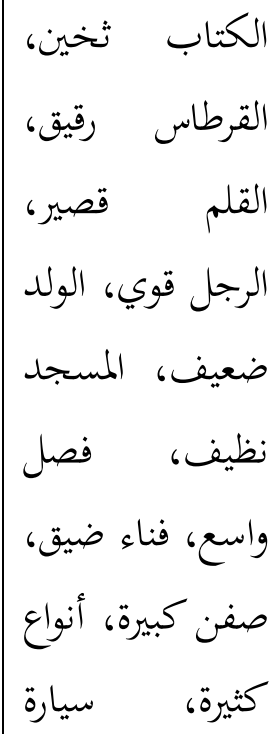 & والأوصاف & $1 \leq$ & $1 \leq$ \\
\hline
\end{tabular}




\begin{tabular}{|c|c|c|c|}
\hline مواد التراكيب & التراكيب & الدرس & الرقم \\
\hline احمل، احفظ، الحضر، & & & \\
\hline 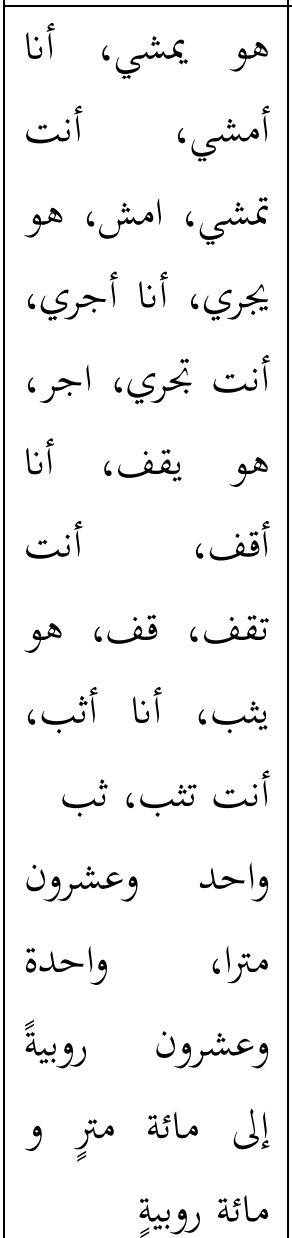 & 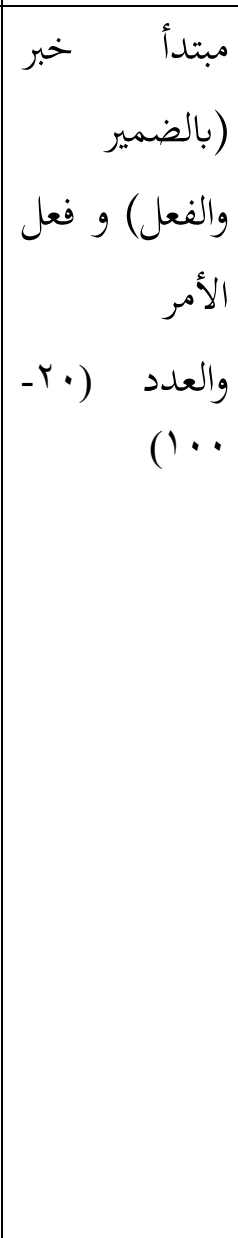 & Yr & Y \\
\hline- & - & r & r \\
\hline 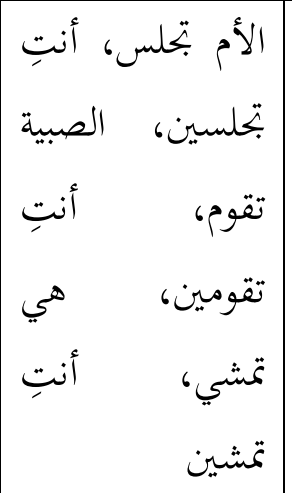 & 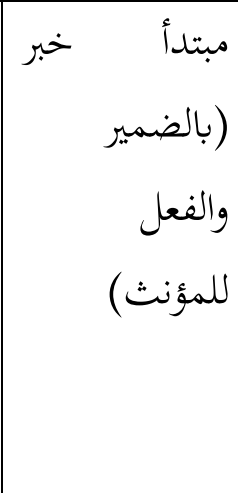 & $r \varepsilon$ & $T \varepsilon$ \\
\hline مائةُ - تسعمائة & العدد $\ldots$ & ro & ro \\
\hline
\end{tabular}

\begin{tabular}{|c|c|c|c|}
\hline مواد التراكيب & التراكيب & رقدم & الرقم \\
\hline- & - & IV & IV \\
\hline 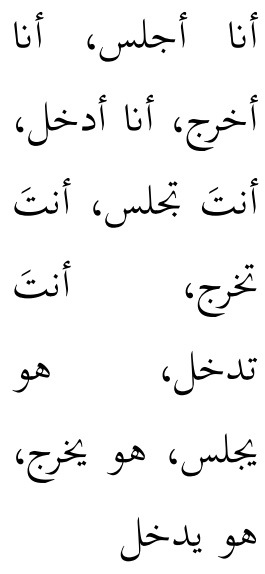 & مبتدأ $\quad$ خبر & 11 & 11 \\
\hline 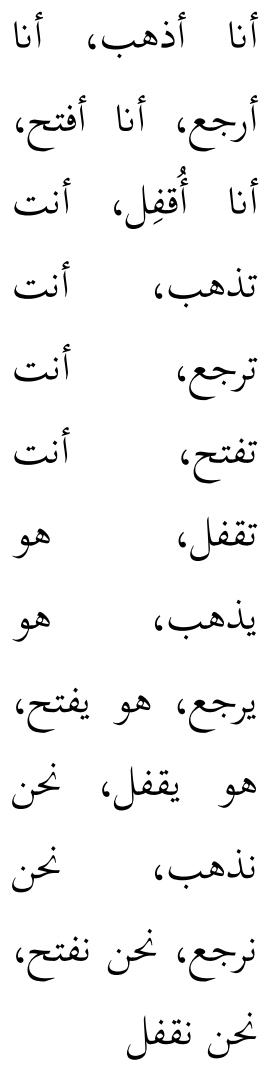 & مبتدأ & 19 & 19 \\
\hline 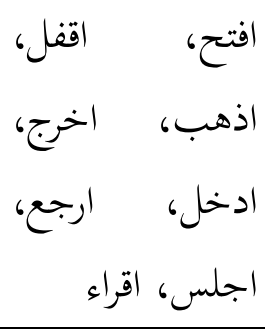 & فعل الأمر & $r$. & $r$. \\
\hline خذ، اكتب، & فعل الأمر & r) & r) \\
\hline
\end{tabular}


لا شكّ أن اللغة العربية محتاجة في التفقّم عن

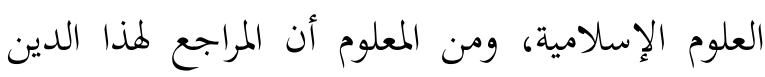

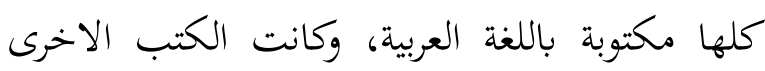
تأخذ أو تنقل المادة الأصلية من هذه الكتب العبلة العبية.

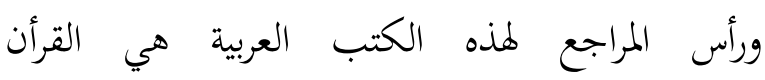
والأحاديث النبوية الشريفة وكانتا أيضا باللغة العربية.

فربما نستطيع أن نقول لايمكن الشخص الذي

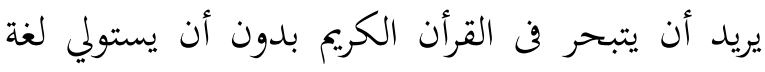

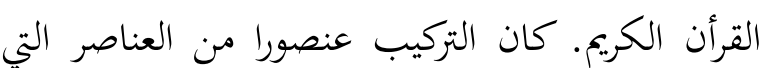

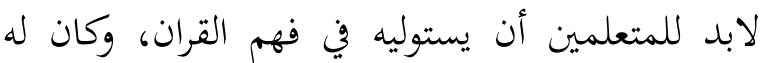
علاقة قوية في اللغة العربية، وكان الفهم فن اللغة العربية

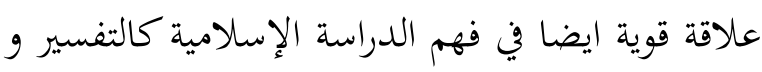
الحديث وغير ذلك.

على سبيل المثال نأخذ كلمة " الايمان والكفر"، كاناتان هاتان كلمتان تصدران منهما الأثر العظيم عند العلماء والمسلمين حتى تصدر من آرائهم عن هاتين كلمتين المسألة السياسية والمذاهب العقيدة المتنوعة كمثل الجبارية والقدرية والمرجئة والمعتزلة وأهل السنة والجماعة.

من منبع اختلاف المتهاين في آرائهم هي اللغة العربية كالنحو والصرف والدلالة. عند المفسرين أيضا كان منبع الاختلاف فن تفاسيرهم هي اللغة. وأيضا عند الأصوليين والفقهاء كان منبع اختلافهم هي اللغة اللعربة. ومن هذه كلها عرفنا أن اللغة العربية

\begin{tabular}{|c|c|c|c|}
\hline مواد التراكيب & التراكيب & الدرس & الرقم \\
\hline 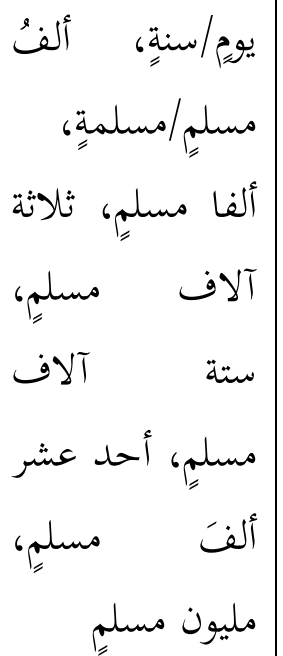 & والتعبير & & \\
\hline
\end{tabular}

ما وجدت الكاتبة المواد الخاصة لدرس التراكيب النحوية، إنما وضع المؤلفان هذا الكتاب الكوان التهات التركيب النحوية مباشرة في الجمل المواقفة بالقواعد، مناسبا بالهدف من تأليف هذا الكتاب هو التطبيق

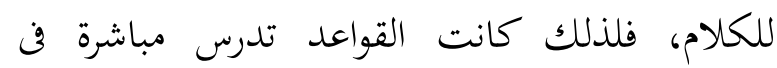

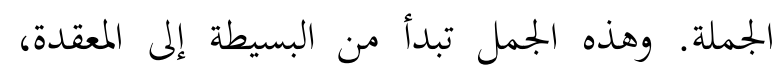
وهي تتناسب مع قدرات الطلاب. التدريب عليها بصورة كافية.وأنواع تدريب لندات الفراب على بناء التراكيب اللغوية منها التكرار، الاستدلال، السؤال والجواب، التحويل، تكوين الأسئلة، وغيرها.

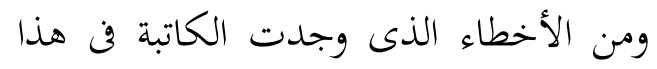
الكتاب من حيث التركيب عن العدد في الدرس ونداء الثالث عشر، كتب هناكثمانيةعشرة رسالة، الصحيح هوثمانيعرة رسالة.

15 Chatibul Imam, Aspek-aspek Fundamental dalam Mempelajari Bahasa Arab, (Bandung: al Ma'aif, 1980), h.5.

أهمية معرفة التراكيب في فهم النصوص

الإسلامية 
لها أهمية عظيمة في التعلم والتفهم عن الدراسة النحوية مباشرة في الجمل الموافقة بالقواعد، مناسبا بالمدف من تأليف هذا الكتاب هو التطبيق للكلام، الاسلامية.

فلذلك كانتالقواعد تدرس مباشرة في الجملة. وهذه

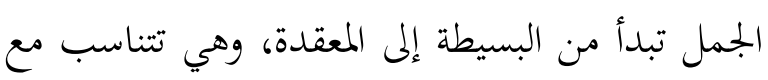
قدرة الطلاب.

اعتمادا على عرض البيانات وتحليلها

من المعلوم أن الاستيلاء عن التراكيب مهمة سابقاعن محتوى كتاب دروس اللغة العربية الجزء الأول

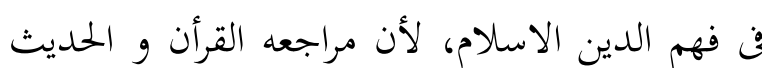
وكتب العلماء القديية وكلها باللغة العربية. للإمام الزركشى والإمام الشبانى من حيث العناصر اللغوية (التراكيب)، تقدم الكاتبة نتيجة البحث هي أن ما وجدت الكاتبة المواد الخاصة لدرس التراكيب النحوية، إنما وضع المؤلفان هذا الكتاب التراكيب 


\section{DAFTAR KEPUSTAKAAN}

Abdullah, Umar al Shadiq. 2008. Ta'lim al Lughah al 'Arabiyyah li al Nathiqin bi Gairiha, Khurtum: al Dar al Alamiyyah.

al Fauzan, Abdurrahman bin Ibrahim. 1428H. I'dad Mawad Ta'lim al Lughah al 'Arabiyyah li Ghairi al Nathiqin biha. t.t: t.p.

al Khauli, Muhammad Ali. 1989. Asalib Tadris al Lughah al 'Arabiyyah. Riyad: t.p,.

al Siman, Muhammad Ali. 1982. al Taujih fi Tadris al Lughah al 'Arabiyyah. Kairo: Dar al Ma'arif.

Arifin, Zainul. t.th. Mawad Dirasah fi Thuruq Ta'lim al Lughah al 'Arabiyyah. Padang: t.p.

Thu'aimah, Rusydi Ahmad. 1985. Dalil 'Amal fi I'dad al Mawad al Ta'limiyah li Baramij Ta'lim al 'Arabiyah. Makkah: Ummul Qura. Manahijuba. Rabat: Isesco.

Umam,Chatibul. 1980. Aspek-aspek Fundamental dalam Mempelajari Bahasa. Bandung: al Ma'arif.

Lufri. 2005.Metodologi Penelitian.Padang: Universitas Negeri Padang. 
Halaman ini tidak disengaja kosong 